\section{Conferência Nacional de Saúde: desafios para o país}

\author{
The Brazilian National Health Conference: \\ challenges for the country
}

\section{Conferencia Nacional de Salud: retos para el país}

\begin{abstract}
This article was published in the context of the upcoming 15th Brazilian National Health Conference and addresses the country's health challenges based on the history of previous conferences. The authors analyze the evolution of health as a public policy agenda, highlighting the role of such institutions as the Brazilian Center for Health Studies (CEBES), the Brazilian Association of Collective Health (Abrasco), and the $\mathrm{Na}$ tional Health Council in advocating and establishing the Brazilian Unified National Health System (SUS). The article also focuses on expectations concerning the 15th National Health Conference within a political and economic scenario that raises questions and challenges both for the future of health policy, exemplified by SUS, and the current capacity to mobilize stakeholders.
\end{abstract}

Health Conferences; Unified Health System; Public Health Policy

\section{Resumo}

O presente artigo, publicado no contexto da realização da 15a Conferência Nacional de Saúde (15 CNS), aborda os desafios do país na área da saúde a partir do histórico das conferências anteriores. Buscou-se contemplar a evolução da saúde como pauta de políticas públicas, observando a atuação de instituições como o Centro Brasileiro de Estudos de Saúde (CEBES), a Associação Brasileira de Saúde Coletiva (Abrasco) e o Conselho Nacional de Saúde na defesa e constituição do Sistema Único de Saúde (SUS). Há, também, destaque para as expectativas em torno da $15 \underline{a}$ CNS e sua realização em um cenário político e econômico que traz diversos questionamentos e desafios, tanto em relação ao futuro da política de saúde exemplificada através do SUS, quanto em relação à capacidade de mobilização de atores neste cenário.

Conferências de Saúde; Sistema Único de Saúde; Políticas Públicas de Saúde 
“Torna-se fundamental a retomada da comunicação direta com as entidades da sociedade e movimentos sociais, democratizando todas as informações do que está acontecendo com o SUS: seus benefícios à população, mas também seus obstáculos e consequências. Essa comunicação social deve se dirigir igualmente a todos os usuários do SUS: os que só têm o SUS e os que, além do SUS, são consumidores de planos privados, a começar dos trabalhadores sindicalizados. Seria a retomada da predominância da consciência e mobilização dos direitos humanos de cidadania. A força social capaz de mudar a política de Estado só acontece com a consciência social, politização e ampla mobilização, incluindo os trabalhadores e as classes médias" 1 (p. 6).

A saúde é um direito humano, coletivo e individual que expressa a possibilidade de articulação virtuosa das políticas sociais e de desenvolvimento, aliando crescimento, inovação, equidade e inclusão social. Para muitos analistas, é nela que se conforma, positiva ou negativamente, nossa modernidade ${ }^{2}$. As condições para realizar os ideais da reforma sanitária pertencem, portanto, a esferas muito mais amplas: a justiça social e a construção de uma democracia substantiva; a ampliação da base social dos que defendem a saúde como direito fundamental; a reforma de Estado; o estabelecimento de responsabilidades sanitárias e instrumentos de proteção dos direitos dos cidadãos; o aprimoramento da participação e controle social; a superação do subfinanciamento; a universalização da cobertura; a resolutividade e a valorização dos trabalhadores de saúde.

Todas essas condições parecem hoje ideais bastante distantes em face à gravidade da situação e de um cenário prospectivo pouco promissor, a depender para sua reversão de uma forte consciência sanitária e mobilização social, que não parecem estar entre as tendências do movimento social.

O processo político e ideológico em curso em nosso país comprova a concepção de Santos \& Menezes 3 sobre a ascensão de um fascismo social convivendo com a democracia liberal. Centrado no binômio apropriação/violência, ao invés da dinâmica precedente de tensão entre regulação/emancipação, esse fascismo social apresenta entre suas formas o fascismo contratual, o qual institui o contrato individual do consumo de serviços privatizados em substituição ao contrato social presente no Estado Providência e no Estado Desenvolvimentista:

"Como regime social, o fascismo social pode coexistir com a democracia política liberal. Em vez de sacrificar a democracia às exigências do capitalismo global, trivializa a democracia até ao ponto de não ser necessário, nem sequer conveniente, sacrificar a democracia para promover o capitalismo. Trata-se, pois, de um fascismo pluralista e, por isso, de uma forma de fascismo que nunca existiu. De fato, é minha convicção que podemos estar a entrar num período em que as sociedades são politicamente democráticas e socialmente fascistas" 3 (p. 47).

A realização da 15a Conferência Nacional de Saúde (CNS) acontece, portanto, em momento de grandes desafios para todos os que vêm construindo o Sistema Único de Saúde (SUS) no país. Vivemos um paradoxo que precisa ser resolvido, se quisermos romper positivamente a encruzilhada de realização ou regressão do ideário da Reforma Sanitária.

Em um quadro de recessão econômica, de perda de base social e baixa iniciativa política do polo progressista, de iniciativas legislativas de forte conteúdo regressivo, de ameaça à governabilidade e, mesmo, à continuidade do poder executivo, necessitamos com urgência e sentido de sobrevivência, conformar agendas e processos que galvanizem a mobilização social em torno de um projeto que tem a dimensão de projeto nacional e de modelo de sociedade, superando a forma fragmentada de articulação de propostas e expressão de interesses.

Todos os momentos fortes da história da saúde no Brasil resultaram da capacidade de articular as agendas setoriais a temas e movimentos de amplitude nacional. Foi assim com Oswaldo Cruz e o movimento higienista do início do século passado, que conquistaram para a ciência e as ações de saúde forte protagonismo em frentes simbólicas e de modelo de desenvolvimento econômico, constitutivos de nossa nacionalidade e do fortalecimento do papel do Estado, e que influenciaram profundamente nossa história. Foi assim, também, no movimento da reforma sanitária e sua relação intrínseca com a luta pela redemocratização do país e afirmação dos direitos de cidadania. Não por acaso, entidades como o Centro Brasileiro de Estudos de Saúde (CEBES), a Associação Brasileira de Saúde Coletiva (Abrasco) e o próprio Conselho Nacional de Saúde vêm ressaltando a necessidade de colocar a saúde no centro do modelo de desenvolvimento nacional.

Ao propor como tema Saúde Pública de Qualidade para Cuidar Bem das Pessoas: Direito do Povo Brasileiro, o Conselho Nacional de Saúde partiu de um balanço positivo quanto à situação da população brasileira após 27 anos de implantação do SUS, com melhoria dos indicadores sociais na última década, apontando com propriedade, entretanto, sérios problemas não equacionados e ameaças de retrocesso e perda 
dos direitos assegurados pela Constituição Federal de 1988 4. Contribuir para a avaliação desse contexto, problematizar o papel da Conferência e indicar alguns caminhos possíveis para que essa instância seja parte de um processo político de afirmação do SUS em um momento adverso é o principal objetivo deste texto.

\section{Conferências Nacionais de Saúde: espaço de articulação e de legitimação de propostas}

A 1ạ CNS aconteceu em 1941 em plena ditadura varguista do Estado Novo. Em um processo de forte centralização política, tratou-se de definir junto a um reduzido grupo de interlocutores - todos vinculados ao governo - os rumos da saúde pública, sendo esta concebida de forma muito restrita. É importante chamar a atenção de que mesmo sob essa perspectiva limitada, a Conferência já assumia o papel de efetuar, no campo da saúde, o concerto e a legitimação de propostas junto a segmentos que deveriam ser mobilizados para viabilizá-las 5 . Mudou ao longo dos anos a natureza do mandato, dos processos e atores, mas perdurou a perspectiva normativa de um lócus de atualização da política nacional de saúde 6,7,8.

No processo histórico de afirmação da reforma sanitária e do controle social, foi emblemática a realização, em 1986, da 8a CNS, caracterizada pela ampliação da participação social na escolha dos delegados e pela profunda revisão dos conceitos de saúde, direito social e papel do Estado, já anunciados no documento do CEBES, $A$ Questão Democrática na Área da Saúde, lido por Sergio Arouca no Simpósio de Saúde da Câmara dos Deputados, em 1979. A 8a resultou de amplo processo de mobilização social com representação do governo e da sociedade civil e foi precedido de pré-conferências nos estados. Foi uma conferência fundadora a ponto de o então Presidente da República José Sarney, em seu discurso de encerramento da etapa nacional, mencionar que o relatório aprovado naquela plenária materializava a pré-constituinte da saúde.

É preciso, ao revisitar a 8a $\mathrm{CNS}$, considerar o contexto que possibilitou a discussão ali desenvolvida, resultado de um forte movimento pela redemocratização, congregando as mais diversas forças sociais, gerando coalizões, articulações e acordos que deram origem à nossa Constituição Cidadã.

No âmbito dos movimentos sociais, já verificamos desde a segunda década de 1970 sinais de transformação das formas clássicas de organização do movimento social, até então concentrada em partidos e sindicatos tradicionais. Nele, ocorreu o auge da presença sindical no ABC Paulista, a criação do Partido dos Trabalhadores (PT) e dos chamados novos movimentos sociais, expressão da diversificação de interesses e fundamentos para a vida associativa e a militância política. Enfim, no nascedouro da Constituição de 1988, havia toda uma conjuntura que permitiu avanços muito mais profundos do que, de fato, a base social do país parecia indicar, e como exemplo destes avanços, podemos citar todo o título da Ordem Social e, em particular, o capítulo da Seguridade Social e sua seção sobre a Saúde.

As conferências seguintes, realizadas no período democrático, tiveram de lidar com os paradoxos de um SUS universal e baseado no princípio da integralidade, nos marcos do que alguns autores denominam wellfare state tardio, defrontando-se com o contexto internacional pautado por projetos neoliberais e sua presença nas políticas do Estado brasileiro durante a década de 1990. Duas coletâneas trazem, com base em perspectivas de diferentes autores, uma ampla discussão sobre o contexto de implantação do SUS: Lima et al. ${ }^{6}$ e Giovanella et al. ${ }^{9}$. No Brasil, a crise do final do Governo Sarney e a ascensão de Fernando Collor marcaram fortemente essa inflexão.

Até a 11ạ, as conferências produziram efeitos significativos resultantes de agendas constitutivas do processo de implantação do SUS. A 9a CNS, em especial, com sua chamada de Municipalização é o Caminho, contribuiu para a descentralização e o papel dos municípios e para a realização das conferências estaduais e municipais preparatórias como etapa obrigatória da conferência nacional. Começou, em seguida, um processo expressivo de aumento do número de resoluções. De 49 na 8a para 253 na 9ạ, com novo salto a partir da 11ạ, com 296 resoluções, chegando a 857 na 13 a ${ }^{8}$. Como expressão da maior diversidade dos interesses nela representados, a ausência de uma condução política mais hegemônica, essa explosão de resoluções coloca em questão a possibilidade de definir diretrizes, identificar prioridades e obter a concretização das recomendações fundamentadas nos resultados dessa instância tão relevante e inovadora no que se refere à pactuação social 8 .

O balanço da experiência das três conferências mais recentes $(14 \underline{a}-2011,13 \underline{a}-2008$ e $12 \underline{a}$ - 2003) vem indicando dificuldades de diálogo e articulação política entre os participantes do movimento sanitário tradicional, gestores e os novos atores sociais representados nos encontros 7,8. É também recorrente, e até então, sempre frustrado, o propósito de Ministros, Conselhos de Saúde e entidades de realizarem uma profunda 
revisão do sentido e organização da CNS. Nesse processo, é comum a nostalgia da 8 a CNS, que incorpora um caráter quase mítico na história da saúde pública e do controle social. Diante da avaliação de que as últimas conferências não vêm dando conta de seus objetivos centrais, há sempre o desejo de "fazer uma nova 8a". É preciso, entretanto, enfatizar que essa avaliação crítica não desconhece a importância e resultados das conferências, inclusive o forte efeito de abertura à participação e inclusão política, a incorporação de temários plurais e de propostas nas políticas e marcos normativo e legislativo.

A efetividade das CNS adquire um sentido maior quando pensada no contexto da "arquitetura participativa no país” e, em especial, sua conformação com base na "orientação participacionista” inaugurada no Governo Lula, uma vez que as CNS têm sido referência emblemática para iniciativas em outras áreas setoriais ou relacionadas a direitos de cidadania. Essa arquitetura participativa comporta, entre outras instâncias e processos, os conselhos de políticas públicas, as conferências e o orçamento participativo. No âmbito federal, existem 64 conselhos, sendo que 13 foram criados no Governo Lula. Houve ampliação de temas e edições de conferências. Entre 1988 e 2009, ocorreram 88 conferências, sendo que 55 delas realizadas entre 2003-2009, com 31 temas novos que mobilizaram, no período de 2003-2012, mais de sete milhões de participantes 10,11 .

Em outubro de 2014, a proposta da Política Nacional de Participação Social (Decreto no 8.243/2014) que reforçava a presença dessas instâncias na formulação de políticas e gestão pública, articulando-as de forma mais sistêmica, foi derrota por iniciativa da Câmara dos Deputados com argumentos de "bolivarianismo". Está em questão, portanto, não apenas o resgate das conferências de saúde, mas o debate sobre as formas institucionalizadas de participação social e gestão participativa, ou, em dimensão mais ampla, as questões que dizem respeito à democracia substantiva em nosso país.

\section{5ạ CNS: desafios e possibilidades}

No âmbito do planejamento e realização da 15a CNS, o horizonte não é, obviamente, a reprodução ou mesmo o resgate do sentido fundador que permeou aquele evento emblemático do movimento pela Reforma Sanitária. O desafio é de interpretar a evolução das conferências em busca de novos caminhos.

Da década de 1980 para cá, os atores mudaram significativamente. O grau de concentração das interlocuções implodiu e emergem novas formas de participação social no mundo e no país. A despeito das críticas que possam ser feitas aos movimentos de junho de 2013, no que toca à fragmentação, desinstitucionalização, espontaneísmo, estes deram visibilidade a novas forças sociais e evidenciaram o enfraquecimento das formas clássicas de representação e luta política, especialmente no caso dos partidos e sindicatos.

Esse cenário sociopolítico em transformação influenciou o processo de convocação e mobilização da 15a CNS. Preocupação que reflete, por exemplo, no regimento interno aprovado pelo Conselho Nacional de Saúde, em que foi prevista, além das tradicionais etapas municipal, estadual e nacional, uma etapa prévia de mobilização, constituída por plenárias populares, realizadas ao longo de março nas cinco regiões do país, e pela 19ạ Plenária Nacional de Conselhos e Movimentos de Saúde, que ocorreu em Brasília, no mês de abril 11 .

A ideia foi de a etapa prévia se constituir em um espaço-tempo formativo, que permitisse o acúmulo de discussão, e que atraísse para o processo setores sociais até então alijados do debate sobre saúde pública. Nessa direção, tiveram livre acesso a cada um desses eventos quaisquer organizações, movimentos ou grupos organizados que desejassem participar e não apenas as instâncias formalmente representadas em conselhos de saúde. Embora não tenham caráter deliberativo, ou eleito delegados, as plenárias populares (regionais e nacionais) constituem pré-requisito para a participação na etapa nacional da 15a CNS como convidados previstos pelo regimento interno, com direito a voz - não a voto - tanto nas plenárias quanto nos grupos de trabalho (o regimento interno da $15 \underline{\text { a }} \mathrm{CNS}$ prevê a participação, na etapa nacional, de 3.248 delegados - com direito a voz e voto -, 956 convidados - com direito a voz - e 98 participantes de credenciamento livre - com direito a voz nas plenárias).

Vale ressaltar que a chamada "etapa de mobilização” prosseguiu mesmo após iniciadas as etapas deliberativas (municipal e estadual), por meio, principalmente, das chamadas "Conferências Livres”, que radicalizam a proposta de abrir a discussão à maior variedade possível de atores sociais. Essas conferências podem ser mais genéricas, como a que aconteceu na Parnaíba, no Piauí, ou mais específicas, como a realizada no Distrito Federal sobre saúde da população negra. Podem aglutinar atores variados, como a Conferência Livre mobilizada pela Central Única dos Trabalhadores em Belo Horizonte (Minas Gerais), ou voltar-se a segmentos determinados, como foi o caso da Conferência Livre realizada no 
Rio Grande do Sul, cujo chamamento dirigia-se, principalmente, para a comunidade acadêmica.

Certamente esse processo de abertura não ocorre sem tensões ou enfrentamentos. Há quem veja no processo o risco de enfraquecimento do sistema de controle social, caso não seja bem resolvida a equação consulta/democracia direta vis-à-vis institucionalidade/deliberação delegada. Entretanto, me parece meritório abrir a pauta da saúde para o conjunto da sociedade, pois certamente uma das origens da profunda crise que hoje atravessa o SUS tem a ver com a dificuldade do seu enraizamento social. O desafio metodológico central é o de produzir, ao mesmo tempo, o enriquecimento - sem dispersão - das resoluções e reforçar o sentimento de pertencimento e relevância dos que participaram das Plenárias Populares e Conferências Livres. Considerando que a agenda mais uma vez é muita ampla, com oito eixos (direito à saúde; garantia de acesso e atenção, participação social; valorização do trabalho da educação e saúde; financiamento do SUS e relação público e privado; gestão do SUS e modelos de atenção à saúde; informação, educação e política de comunicação do SUS; ciência e tecnologia inovação do SUS; reformas democráticas e populares do Estado), cada um dos quais já comportando um vasto campo, torna-se imperativa a confecção de documentos de referência sintéticos e a limitação do número de resoluções para que se atenha ao essencial.

Seja como for, torna-se crucial relacionar os temas da mobilização e da representação a um projeto de forte articulação política em torno do SUS, condição para que a diversificação dos setores representados na $15 \underline{\text { a }} \mathrm{CNS}$, defendendo suas pautas específicas e legítimas, não se restrinja à afirmação de identidades desconectadas de um projeto coletivo.

Esse ponto tem sido objeto das discussões e de todo o intenso esforço de mobilização e proposição coordenado pelo Conselho Nacional de Saúde. Para avançar nessa direção é necessário acentuar as possibilidades de construir unidade política em meio às tendências contemporâneas de maior fragmentação dos movimentos sociais. Pensar e buscar contribuir para a construção de cenários desejáveis e possíveis para o SUS é um componente essencial do processo político em curso.

Não é o objetivo realizar um balanço do SUS, seus avanços e retrocessos. A literatura tem excelentes trabalhos nesse sentido e muito se produziu recentemente quando da reflexão sobre os 25 anos do SUS 13. A imagem de capa do Radis número 127 de abril de 2013, "um copo meio cheio, meio vazio", tem sido muitas vezes o tom para realizar o inventário dos fracassos, sem descurar do reconhecimento dos avanços 10. Nelson Rodrigues dos Santos sistematiza de outra forma esse percurso, por meio da caracterização e confronto das "estratégias construtoras do SUS" e seu reverso, as "estratégias impeditivas e desconstrutoras". Interessa destacar que ganha força a previsão de notórios analistas e militantes do SUS, de um cenário regressivo cuja superação seria improvável ou quase utópica. No caso de Nelson Rodrigues dos Santos, essas estratégias impeditivas e desconstrutoras do SUS são evidentemente mais fortes e hegemônicas, a ponto de se constituírem como estratégias construtoras de outro sistema e outra política pública de Estado, recebendo o nome de "Cobertura Universal Pública e Privada". Por sua vez, Gastão Wagner de Sousa Campos 14 (p. 1), utilizando a expressão "ex-possível" de Clarice Lispector - "fenômeno plausível no passado, mas que o descuido humano sistemático haveria esvaziado de suas possibilidades de vir a ser", adota premissas fortemente negativas e propõe o "SUS Brasil", como "hipótese desesperada e utopia concreta":

"A primeira hipótese triste é que o Sistema Unico de Saúde (SUS) transformou-se, com o tempo, em um 'ex-possível'. (...) A segunda hipótese desesperada (...) é a de que o SUS está sedo derrotado no simbólico, no "coração e na mente" dos brasileiros. (...) A terceira hipótese desesperada é a de que não há no horizonte nenhum projeto político que se proponha explicitamente a enfrentar o conjunto de impasses crônicos que limitam e restringem a plena constituição do SUS e do direito à Saúde" 14 (p. 1).

Abro aqui um parêntese. Apesar de não caber neste artigo uma análise crítica do SUS Brasil, a visibilidade da proposta e seu potencial heurístico me leva a destacar contrapontos e ceticismo: a excessiva ênfase na autarquização frente à ineficiência desse modelo na atual configuração da administração pública; conferir ao Conselho Nacional de Saúde a tripartite função de planejamento e gestão; finalmente, de outro plano, a baixa viabilidade de reconfiguração federativa com "Regiões de Saúde Autarquizadas" sob a governança de um "Secretário Regional de Saúde”, indicado por "Conselhos Regionais de Saúde" 14.

Pelo lado das estratégias construtoras, devese ressaltar que, passados 27 anos, houve avanços significativos, com a ampliação do acesso aos serviços de saúde, especialmente para aqueles milhões de pessoas que não possuíam vínculo formal de emprego, e a implantação de programas como a ampliação da atenção básica, por intermédio da Estratégia Saúde da Família, o Programa Nacional de Imunização e o combate a agravos específicos, a exemplo do programa de HIV/AIDS. 
Destaco, também, entre as iniciativas mais recentes por seus efeitos imediatos de grande magnitude e propósito estruturante, o Programa Mais Médicos para o Brasil, destinado a garantir o acesso à atenção médica para milhões de brasileiros, e que enfrenta o desafio de conferir protagonismo ao Ministério da Saúde na modelagem da formação dos profissionais de saúde para adequá-la às necessidades de saúde da população.

Nos últimos 15 anos, a formulação teórica e a implantação de políticas, leis, normas infralegais e aparatos institucionais intersetoriais relacionadas ao Complexo Econômico-Industrial da Saúde (CEIS), sob a coordenação do Ministério da Saúde, trouxeram uma novidade com enorme potencial de concertação entre as políticas do SUS, o setor produtivo e a sociedade, em torno de um projeto nacional inclusivo. O CEIS é um referencial teórico que propõe a articulação entre direitos, políticas sociais e desenvolvimento econômico. O conceito é baseado na premissa de que a saúde se constitui, simultaneamente, como um direito de cidadania e uma frente de desenvolvimento e inovação estratégica na sociedade, e que a articulação virtuosa destas duas dimensões é central para a conformação de um modelo de desenvolvimento inclusivo e para a sustentabilidade do SUS 15. Sua importância é ressaltada no documento de orientação aos debates da 15a CNS, que traz entre os objetivos, o de fortalecer o complexo industrial da saúde para expandir a produção nacional de tecnologias estratégicas e a inovação em saúde 4 .

No polo das estratégias desconstrutoras, os binômios desfinanciamento e privatização, e território e governança sintetizam os maiores desafios que, entre outras consequências, vêm solapando um dos pilares do SUS, a universalidade. De acordo com a Constituição brasileira, a universalidade exige a consolidação de sistemas de saúde públicos e universais, com integralidade e equidade, o que efetivamente não atingimos. Esse quadro desfavorável tem sua tradução no embate nos fóruns internacionais entre a concepção de "sistemas universais" e a "cobertura universal" restrita" 16 . Da mesma forma, temos no polo negativo a precarização do trabalho em saúde e ausência de uma perspectiva integrada e efetiva de cargos e carreiras profissionais do SUS.

Vista com base na perspectiva anteriormente esboçada, a realização da 15a CNS traz o duplo desafio de reafirmar a relevância desse instrumento para a gestão democrática e mobilizar a sociedade para a superação do paradoxo do SUS diante de condições tão desfavoráveis: crise econômica, crise de condução política, crise de valores, baixa adesão ao debate e compreensão popular do que é este nosso projeto de saúde pública. Some-se a isso um congresso conservador e um avanço da internacionalização do capital e do setor privado, associado a iniciativas que rompem com toda a lógica do SUS e que galvanizam também desejos e aspirações populares, como no exemplo da Proposta de Emenda à Constituição (PEC no 451/2014. http://www.camara.gov. $\mathrm{br} /$ proposicoesWeb/fichadetramitacao?idPropo sicao $=861000$, acessado em 24/Jul/2015), de autoria do Deputado Eduardo Cunha, que obriga os empregadores a pagarem planos de saúde para os trabalhadores.

O cenário nacional aponta ainda para um novo e paralelo modelo sendo gestado, indo além de nossa tradicional perspectiva de, ao considerarmos o setor privado, focalizarmos a assistência médica e hospitalar. Verifica-se que ações de atenção primária, promoção, ensino e pesquisa estão sendo desenvolvidas e estruturadas pelos grandes grupos hospitalares privados, ocupando as lacunas que o poder público está deixando.

Contraditoriamente, considerando o processo eleitoral de 2014, não se registra o mesmo "desmonte" do SUS nos discursos políticos. Não houve candidato à Presidência da República que defendesse o fim do SUS. Pelo contrário: pela primeira vez em debates políticos (inclusive aqueles veiculados pela televisão) o sistema foi "chamado pelo nome" por vários candidatos. Nenhuma campanha defendeu enfaticamente a privatização da saúde 17. Desse fato é possível inferir que a ideia de uma saúde universal, integral e gratuita encontra eco na sociedade. Entretanto, sem explicitar a intenção central de desconstruir o direito universal à saúde e a obrigação do Estado de provê-la, inscritos em nossa constituição, a mídia concentra suas baterias explorando negativa e sistematicamente a realidade do SUS.

Por outro lado, é entre os defensores do SUS como sistema universal, pautado pela equidade $\mathrm{e}$ integralidade, que se encontra a permanente exposição de projetos e ideias para o setor. Esse cenário dual que verificamos na saúde pública encontrará, sem dúvida, espelhamento no cenário político econômico geral, onde se observa uma falência generalizada dos discursos e projetos coletivos. A busca de um projeto nacional aliando direitos, políticas sociais e base produtiva que se configura no binômio saúde e desenvolvimento e na conformação de um complexo econômico e industrial da saúde induzido e regulado pelo Estado, que já encontrava dificuldades em críticas de setores da esquerda, está em xeque pela falta de sustentação do desenvolvimentismo inclusivo e seu conteúdo de autonomia nacional que caracterizou os mandatos de Lula e o primeiro de Dilma Rousseff. 
Da perspectiva dos setores de esquerda há uma crítica ao modelo que propõe aliar crescimento econômico e atendimento das demandas sociais. Questiona-se a possibilidade de tal concertação entre o nível empresarial e o nível social. Dessa crítica, no entanto, não emergem, tampouco, alternativas viáveis. Na perspectiva dos segmentos pautados pelo neoliberalismo, as repostas são dadas pela discussão de produtividade e de eficiência, ainda que não respondam às demandas sociais. Seja como for, o que observo é a construção de um novo modelo neoliberal cristalizando-se para além de enfrentamentos discursivos.

Que estratégias podem minimizar essa distância entre o discurso legitimado da garantia de direitos e a prática de transformar qualquer direito em mercadoria? Como enfrentar esse embate ideológico? Quais seriam os mecanismos de superação dos grandes desafios da saúde e quais os processos sociais mais qualificados para efetivá-los? A 15a CNS se desenrola em um cenário de busca de respostas a essas perguntas.

\section{A expectativa frente à 15 a CNS}

As agendas do CEBES e Abrasco, dentre outras instituições e fóruns, destacam propostas de Reforma Política, Reforma Tributária, democratização da comunicação da mídia, juntamente com as propostas mais tópicas, a exemplo do fim dos subsídios e desonerações fiscais, taxação de grandes fortunas, fim da Desvinculação das Receitas da União (DRU) e flexibilização da $L e i$ de Responsabilidade Fiscal para a saúde, como substrato para a superação do subfinanciamento, fortalecimento da democracia substantiva e sustentabilidade do SUS.

Tanto essas agendas quanto propostas de modelo organizacional e de governança, a exemplo do "SUS Brasil" de Campos 14, demandam para avaliar sua pertinência, viabilidade e estratégias de implantação de uma capacidade de interlocução mais densa e qualificada, orientada por um esforço de prospecção. Com esse objetivo, a Fundação Oswaldo Cruz vem desenvolvendo, em cooperação com a Secretaria de Ações Estratégicas da Presidência e o Instituto de Pesquisa Econômica Aplicada (IPEA), o projeto Saúde Amanhã.

Nele temos realizado estudos de base que permitem a análise de uma série de temas, de modo a considerar respostas para questões que estão no cerne da encruzilhada em que vivemos: o cenário de SUS universal, integral e equitativo é viável? Em caso afirmativo, quais são as condições que garantiriam sua viabilidade? Qual a conformação desejável e possível do modelo de mix público e privado em nosso país? É possível regular e exercer coordenação efetiva sobre o sistema público e privado? De quanto e com que medidas é possível inverter a prevalência do gasto privado sobre o gasto público? Há que se construir evidência para afirmar que tendências econômicas, políticas, sociais e demográficas estão se configurando e que políticas são viáveis. Na ausência dessa fundamentação, restaria o discurso idealizado ou a tentativa de resolver fragmentariamente a operação do sistema.

O financiamento do setor saúde é questão central para se pensar realisticamente as possibilidades de avanços na construção de um sistema de saúde que atenda o desiderato constitucional de universalidade e equidade. A composição do gasto em saúde no Brasil revela o grande esforço que deverá ser feito para isso. Uma parte significativa da riqueza nacional já é consumida em ações e serviços de saúde. Em 2013, o gasto total em saúde atingiu 9,1\% do Produto Interno Bruto (PIB). Esse padrão não está tão distante de muitos países desenvolvidos. No mesmo período, à guisa de exemplo, o gasto no Reino Unido correspondeu a 8,5\%, na Itália a 8,9\%, na Espanha a 8,9\%, países que têm sistemas universais e equitativos.

Duas diferenças, entretanto, se colocam entre o Brasil e esses países: o montante do gasto per capita e a proporção do gasto público em relação ao gasto total. Em poder de paridade de compra (PPC), o gasto per capita no Brasil foi de US\$ 1.471,00; na Itália, US\$ 3.077,00; no Reino Unido, US\$ 3.235,00; na Espanha, US\$2.928,00. Naquele período, no Brasil, a proporção de gasto público foi de $48,2 \%$ do gasto total em saúde, comparados a $77,4 \%$ na Itália, $83,3 \%$ no Reino Unido e $71,7 \%$ na Espanha (The Organisation for Economic Co-operation and Development. http:// www.oecd.org/els/health-systems/OECDHeal thStatistics-2015-Frequently-Requested-Data. xls, acessado em 24/Jul/2015).

Em 2012, várias entidades da sociedade civil brasileira organizaram-se para propor um aumento dos recursos federais para a saúde no movimento chamado Saúde+10 (http://www. saudemaisdez.org.br), que propunha a destinação de $10 \%$ da receita corrente bruta (RCB) da União para gastos com ações e serviços de saúde. Aquele movimento, após intensa mobilização, resultou num projeto de lei de iniciativa popular encaminhado ao Congresso Nacional em 2013. Entretanto, por inciativa do Governo, foi encaminhada uma proposta de Emenda Constitucional, finalmente aprovada no início de 2015, que estabeleceu a vinculação de $15 \%$ da receita corrente líquida (RCL) a ser atingida em cinco anos 18 .

Esse valor, para efeitos comparativos, corresponderia a um incremento dos gastos da União 
de $18,5 \%$ (contra $46,9 \%$ dos $10 \%$ da RCB). Como a União responde por aproximadamente metade dos gastos do SUS, o que se obterá passados os cinco anos será um incremento de pouco mais de $9 \%$ dos gastos públicos em saúde. Para efeitos de comparação internacional com os países mais ricos citados, que comprometem uma parte semelhante de seu PIB em saúde, isso equivaleria, se aplicado em 2013, a aproximadamente, em per capita (PPC) aos gastos públicos observados na segunda metade dos anos 1980.

Nas projeções efetuadas pela iniciativa Saúde Amanhã em 2013, apenas a mudança na estrutura demográfica, sem alterações tecnológicas ou epidemiológicas significativas - que terão cada vez mais impacto sobre a necessidade de financiamento - produzirá, em vinte anos, um incremento de gastos da ordem de $37 \%$ com a atenção à saúde. Por sua vez, a mais otimista das previsões de crescimento do PIB, a taxa oscilava entre 3 e $4 \%$ ao ano ${ }^{19}$. Para o cenário de 2015, essas estimativas parecem demasiado otimistas. Entretanto, mesmo adotando uma taxa de $4 \%$, no prazo de vinte anos o nosso PIB teria crescido 2,1 vezes. Isso significaria que estaríamos chegando, vinte anos depois, perto dos padrões de gasto per capita da Espanha de hoje. Se levarmos em conta a iniquidade distributiva da atual organização do sistema de saúde brasileiro, com menos da metade do gasto destinado a três quartos da população, estaríamos atingindo apenas os padrões espanhóis de 1995!

Outro problema a ser enfrentado decorre do progressivo enfraquecimento da presença do Estado que, pela necessidade de cortar despesas, passa a delegar suas atribuições a agentes privados e organizações não governamentais, resultando em um hibridismo organizacional com proliferação de diversos arranjos públicoprivado.

Agravada pela tensão inerente aos interesses divergentes entre o setor público e o setor privado, sobressai a própria tensão entre os agentes governamentais, decorrente dos processos de descentralização e municipalização implantados nos anos 1990, com alguns impasses na execução de políticas definidas pelo Governo Federal 20.

Nesse sentido, outra contribuição relevante na direção de construirmos cenários desejáveis e viáveis para o SUS pode ser exemplificada no estudo realizado por Viana et al. 21 , no âmbito do projeto Saúde Amanhã. Os autores, após apresentarem os elementos centrais da crise do modelo de ampla proteção social no Estado contemporâneo e suas relações com o caso específico do SUS, apresentam uma perspectiva integrada para a análise da descentralização do poder regulatório e decisório e do empresaria- mento da oferta de serviços no Brasil. De acordo com eles, sem desqualificar os méritos da descentralização, é preciso lembrar que tratou-se de uma descentralização que, além de não refletir a busca de ganhos de eficiência, não traduziu necessariamente a manifestação das preferências dos governos subnacionais e de seus cidadãos 22 .

Após analisarem os dados do Cadastro Nacional de Estabelecimentos de Saúde (CNES), propõem um exercício de construção de cenários sobre os segmentos institucionais da gestão em saúde, considerando os setores público e privado e levando em conta, entre outras características, o tamanho e a abrangência de cada segmento institucional; a modelagem sistêmica e funcional da atenção à saúde; a preponderância do Direito Público ou Privado; as vinculações ou interações com o SUS; o financiamento público; os vínculos empregatícios e as características da força de trabalho; a competência e a capacidade de regulação estatal e de controle público/social.

A Figura 1 apresenta os três cenários possíveis identificados por Viana et al. 21 .

O primeiro cenário, pluralismo empresariado, de institucionalidade híbrida, sob a égide do Direito Privado estaria associado à dinâmica inercial de consolidação da predominância do segmento privado com fins lucrativos, suplementar ao SUS e sob regulação estatal agenciada. O segundo, pluralismo integrado, de institucionalidade estatal, sob a égide do Direito Público, estaria pautado pela assistência integral, com ênfase redistributiva; universalidade integral com redes regionais de serviços, coordenação federativa; controle direto da maior parte dos serviços de saúde e da promoção de insumos; e maior controle social. Os autores observam que "não se trataria de um processo de 'estatização', propriamente dito, mas de inovação na institucionalidade estatal, com maior provimento e melhor aporte de recursos financeiros para esse setor, além de reordenamento de processos de trabalho e maior integração de cargos e carreiras profissionais do SUS" 21 (p. 16).

Finalmente, no terceiro cenário, pluralismo mercantil, de institucionalidade privada lucrativa, projeta-se a tendência regressiva de privatização preponderante para o conjunto do sistema de saúde com subvenções estatais para oligopólios mercantis de operadoras de planos de saúde, com regulação agenciada. "A característica mais significativa nesse cenário seria a inversão do sentido de complementaridade do setor privado ao setor público, de modo que os segmentos institucionais públicos serviriam de suporte e complemento dos privados" 21 (p. 17).

Não se trata aqui de reproduzir o conjunto de análises e argumentos dos autores, mas de acen- 
Representação esquemática de três tendências e cenários possíveis para a configuração de institucionalidades de gestão em saúde no Brasil horizonte de 2030.

CENÁRIO I: PluRALISMO EMPRESARIAdo COM PREPONDERÂNCIA DE SEGMENTOS HÍBRIDOS DE QUASE-MERCADO (ESTATAL DE ADM. INDIRETA E PÚBLICO NÃO ESTATAL, SOB A ÉGIDE DE DIREITO PRIVADO) E DE SEGMENTO PRIVADO COM FINS LUCRATIVOS, COMPLEMENTARES E SUPLEMENTARES AO SUS. "UNIVERSALIDADE BÁSICA" COM SERVIÇOS FRAGMENTADOS E REDES TEMÁTICAS OU ESPECÍFICAS ESTRUTURADAS, SOB GOVERNANÇA OPERATIVA, COM REGULAÇÃO CONTRATUAL E AGENCIADA

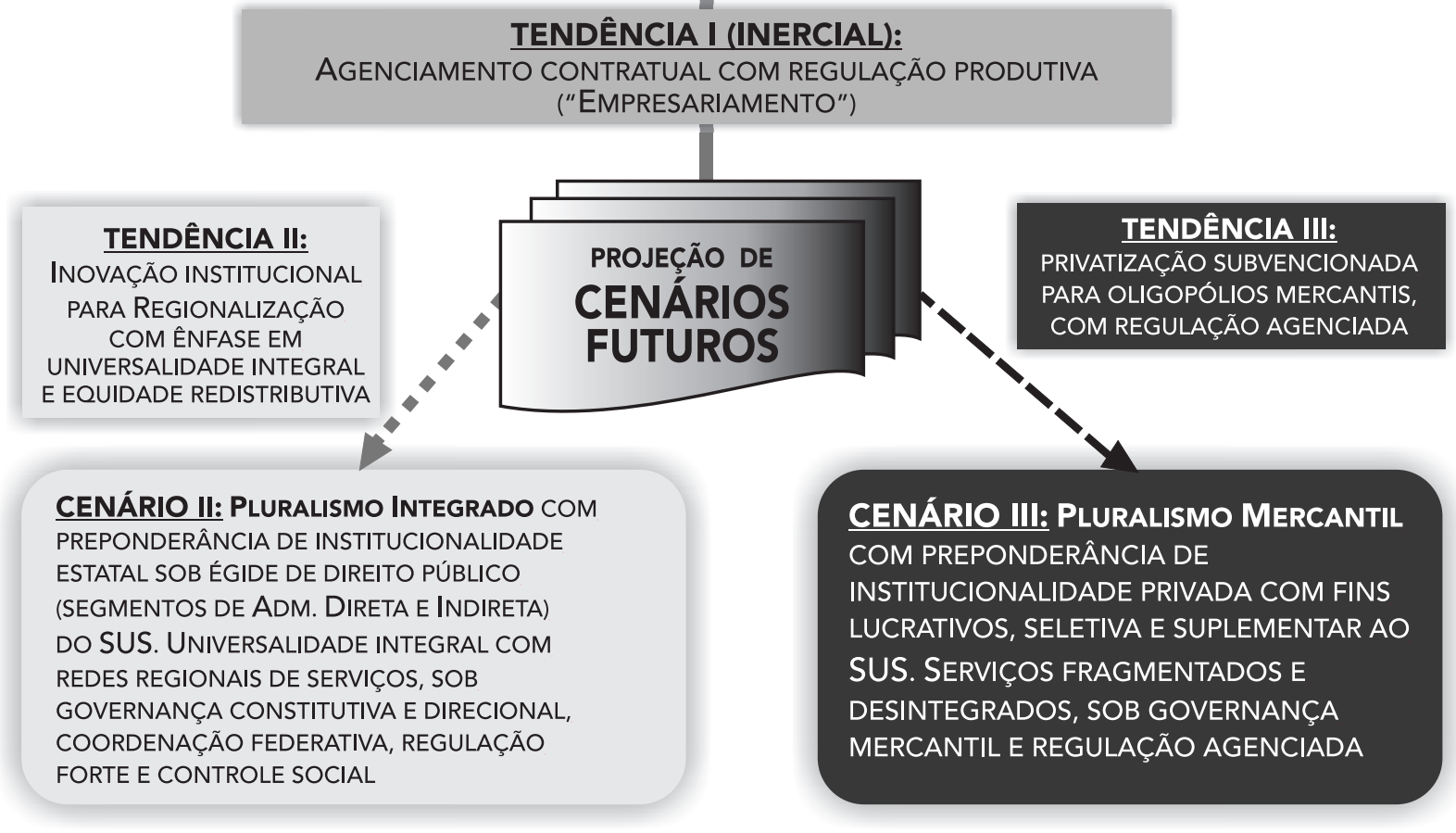

Fonte: Viana et al. 21.

tuar que, do meu ponto de vista, a metodologia de construção de cenários com base em estudos bem fundamentados é crucial para a superação dos impasses que vivemos. Desse modo, o segundo cenário proposto é o que mais aproxima, a meu ver, o SUS ideal de suas reais possibilidades de realização.

Lembro a respeito, a proposta de Boaventura de Sousa Santos de conceber uma nova designação para o Estado como "novíssimo movimento social”, mais ampla que as concepções correntes, na qual "o Estado é o articulador que integra um conjunto híbrido de fluxos, redes e organiza- ções em que se combinam e interpenetram elementos estatais e não estatais, nacionais, locais e globais" 23 (p. 364).

Essa construção pressupõe a refundação democrática da administração pública e do terceiro setor, abrindo-se a possibilidade de um "Estado Experimental", o que leva o autor a postular 23 (p. 372): "A luta democrática é, assim, antes de mais, uma luta pela democratização das tarefas de coordenação. Enquanto antes se tratou de lutar por democratizar o monopólio regulador do Estado, hoje há sobretudo que lutar pela democratização da perda desse monopólio". Ou ainda, “as lutas 
democráticas dos próximos anos sejam fundamentalmente lutas por desenhos institucionais alternativos" 23 (p. 375).

Ainda de acordo com o mesmo autor 23 (p. 375): "transformar-se o Estado num campo de experimentação institucional, permitindo que diferentes soluções institucionais coexistam e compitam durante algum tempo, com carácter de experiências-piloto, sujeitas à monitorização permanente de colectivos de cidadãos com vista a proceder à avaliação comparada dos desempenhos. A prestação de bens públicos, sobretudo na área social, pode assim ter lugar sob várias formas e a opção entre elas, a de ter lugar, só deve ocorrer depois de as alternativas serem escrutinadas na sua eficácia e qualidade democrática por parte dos cidadãos".

A concretização do cenário "pluralismo integrado, de institucionalidade estatal, sob a égide do Direito Público" depende, sobretudo, de fatores abrangentes, como reformas institucionais do Estado Brasileiro (tributária, política etc.), reformas estas que, como já referi, estão no cerne do posicionamento político do Conselho Nacional de Saúde e do CEBES nos documentos preparados para a 15a CNS. Trata-se, portanto, de promover o diálogo e a convergência entre estudos de cenário e as principais teses colocadas pelos atores políticos que vêm coordenando a realização da 15a CNS.

Considerando sua natureza deliberativa e mobilizadora, a CNS seria o espaço para, em suas etapas preparatórias, prospectar cenários e, com base neles, definir o cenário desejável e viável e as estratégias que poderiam concretizá-lo frente à conjuntura e às tendências inerciais ou regressivas de médio prazo.

Não se trata de transformar as conferências em instâncias técnicas, reduzindo com isto sua força mobilizadora, mas de promover o encontro do estudo de cenários com as teses políticas em debate. Historicamente, observa-se esse dilema na realização das conferências: se você focaliza o debate, no intuito de buscar soluções de maior aplicabilidade, corre-se o risco de uma despolitização do processo. De outro lado, se você realiza um debate amplo e mais conceitual, em um momento em que são necessárias soluções, as propostas aprovadas tendem a dormir nos relatórios.

Qualquer debate político consequente precisa considerar cenários e riscos efetivos à proposta que, politicamente, se deseja defender. É preciso superar a ideia de trabalhar com um cenário único, naturalizado com base na reafirmação dos princípios do SUS. É preciso ampliar o debate, mobilizar novos e variados atores, envolver o legislativo, movimentos sociais e o judiciário e
- por que não? - o setor privado, a fim de viabilizar a concertação de novas relações e soluções. A pergunta que se precisa fazer é como transpor a idealização para um processo de transformação social que lhe dê sustentabilidade.

Nessa perspectiva as CNS não devem ser entendidas como a "conclusão" de um processo, mas como ponto de partida de novos processos de agenciamento de interesses, concertação e pactuação do controle social junto aos diferentes atores nem sempre ouvidos durante o processo da conferência. A efetiva produção e posterior execução das políticas começam quando finda a plenária final.

A "15a” traz a oportunidade para que possamos resgatar a capacidade de formulação das instituições e atores comprometidos com o SUS. E isso não significa meramente a afirmação de uma defesa retórica. Estamos diante do desafio de reinvenção do sistema para garantir seus princípios e diretrizes.

\section{Considerações}

Este artigo é escrito num momento de enorme incerteza quanto à conjuntura de sua publicação. Tudo o que for dito poderá perder o sentido, ou adquirir maior relevância, dependendo do desdobramento da atual crise política.

É preciso também alertar que, apesar de ter comparecido a todas as conferências nacionais desde a 8ạ, meu envolvimento mais profundo se deu com a preparação e dinâmica da 12ạ, coordenada inicialmente por Sergio Arouca e, depois de sua morte, por Eduardo Jorge. Fui, juntamente com Sarah Escorel e Ana Maria Costa, relator dessa conferência que ocorreu em um momento de grande expectativa com o primeiro mandato de Lula, primeira experiência do polo de esquerda e do PT na condução do Ministério da Saúde, com Humberto Costa, além da presença icônica de Arouca na coordenação da CNS. O aprendizado com o contraste entre as expectativas iniciais e as frustrações de seus resultados; o tensionamento entre o Conselho Nacional de Saúde e a Secretaria de Gestão Estratégica e Participativa (SEGEPE), criada naquela ocasião e coordenada por Arouca, em torno do sentido de suas missões e relações entre controle social e o executivo; a tentativa frustrada de "realizar uma nova 8ạ", o que implicaria a radical mudança em sua metodologia, desde a escolha de uma vocação de delineamentos estratégicos e consequente construção da agenda, dos documentos de referência e da dinâmica nas três esferas de governo, mantêm certamente atualidade com a análise da 15ạ. Algumas das questões que ali se adensaram, 
adquiriram ao longo desses anos novas facetas e evoluíram para melhor e para pior. Por sua vez, já não tenho a possibilidade de avaliar com a rique- za e legitimidade de quem está imerso no desafio de organizar a 15ạ, em especial os conselheiros e a coordenação executiva da CNS.

\section{Resumen}

Este artículo, publicado en el contexto de la celebración de la 15 a Conferencia Nacional de Salud, nos aproxima a los retos de este país en el ámbito de la salud, siguiendo la estela de las conferencias previas a este respecto. El objetivo es obervar la evolución de la salud, analizando la agenda de políticas públicas, y enfatizando el papel de instituciones como: el Centro Brasileño de Estudios de Salud (CEBES), la Asociación Brasileña de Salud Colectiva (Abrasco) y el Consejo Nacional de Salud por su defensa en la constitución del Sistema Único de Salud brasileño (SUS). Existe también un interés especial por las expectativas generadas entorno a esta $15 \underline{a}$ Conferencia Nacional de Salud, y la celebración de la misma en un escenario político y económico que plantea cuestiones y desafios que afectan el futuro de la política de salud, ejemplificada en el SUS, y en relación con la capacidad de movilización de actores en este escenario.

Conferencias de Salud; Sistema Único de Salud; Políticas Públicas de Salud

\section{Agradecimentos}

$\mathrm{O}$ artigo e réplica, que são da minha exclusiva responsabilidade, contaram com a importante colaboração de Nísia Trindade Lima, Arlindo Fábio Gómez de Sousa, José Noronha, Valcler Rangel e Márcia Corrêa e Castro. Agradeço também a ajuda na coleta de material e revisão do texto de Alex Príncipe e Emília Nazaré, da equipe do Gabinete da Presidência, Fundação Oswaldo Cruz. 


\section{Referências}

1. Santos NR. SUS, política pública de Estado: seu desenvolvimento instituído e instituinte e a busca de saídas. Ciênc Saúde Coletiva 2013; 18:273-80.

2. Kickbusch I, Maag D, Saan H. Enabling healthy choices in modern health societies. http://old. ilonakickbusch.com/health-literacy/Gastein 2005.pdf (acessado em 17/Jul/2015).

3. Santos BS, Meneses MP. Epistemologias do Sul. São Paulo: Cortez Editora; 2010.

4. Conselho Nacional de Saúde. Documento orientador de apoio aos debates da 15a Conferência Nacional de Saúde. Brasília: Conselho Nacional de Saúde; 2015.

5. Hochman G, Fonseca CMO. A I Conferência Nacional de Saúde: reformas, políticas e saúde pública em debate no Estado Novo. In: Gomes AC, organizador. Capanema: o ministro e seu ministério. Rio de Janeiro: Editora FGV; 2000. p. 173-93.

6. Lima NT, Gerschman S, Edler FC, Suárez JM, organizadores. Saúde e democracia: história e perspectivas do SUS. Rio de Janeiro: Editora Fiocruz; 2005.

7. Escorel S, Bloch RA. As Conferências Nacionais de Saúde na construção do SUS. In: Lima NT, Gerschman S, Edler FC, Suárez JM, organizadores. Saúde e democracia: história e perspectivas do SUS. Rio de Janeiro: Editora Fiocruz; 2005. p. 83-119.

8. Conselho Nacional de Secretários de Saúde. SUS 20 anos. Brasília: Conselho Nacional de Secretários de Saúde; 2009.

9. Giovanella L, Escorel S, Lobato LVC, Noronha JC, Carvalho AI, organizadores. Políticas e sistemas de saúde no Brasil. 2a Ed. Rio de Janeiro: Editora Fiocruz; 2012.

10. SUS: a gente quer inteiro e não pela metade. Radis 2013; (127).

11. Pogrebinschi T, Santos F. Participação como representação: o impacto das Conferências Nacionais de Políticas Públicas no Congresso Nacional. Dados Rev Ciênc Sociais 2011; 54:259-305.

12. Conselho Nacional de Saúde. Regimento interno da 15a Conferência Nacional de Saúde. http:// www.conferencia15.org.br/?page_id=12 (acessado em 17/Jul/2015).

13. Paim JS. A Constituição Cidadã e os 25 anos do Sistema Único de Saúde (SUS). Cad Saúde Pública 2013; 29:1927-53.

14. Campos GWS. Uma utopia possível: o SUS Brasil. Radis 2014; (145):16-7.
15. Gadelha CAG, Costa LS. A saúde na política nacional de desenvolvimento: um novo olhar sobre os desafios da saúde. In: Noronha JC, Pereira TR, organizadores. A saúde no Brasil em 2030 - prospecção estratégica do sistema de saúde brasileiro: desenvolvimento, Estado e políticas de saúde. v. 1. Rio de Janeiro: Fundação Oswaldo Cruz/Brasília: Instituto de Pesquisa Econômica Aplicada/Ministério da Saúde; 2013. p. 103-32.

16. Santos BS. A gramática do tempo: para uma nova cultura política. São Paulo: Cortez Editora; 2008.

17. Scheffer M, Bahia L. A saúde nos programas de governo dos candidatos a Presidente da República do Brasil nas eleições de 2014: notas preliminares para o debate. http://cebes.org.br/site/wp-con tent/uploads/2014/07/proposta-saúde-presiden ciaves-2014.pdf (acessado em 24/Jul/2015).

18. Presidência da República. Emenda Constitucional no 86, de 17 de março de 2015. Altera os arts. 165, 166 e 198 da Constituição Federal, para tornar obrigatória a execução da programação orçamentária que especifica. Diário Oficial da União 2015; 18 mar.

19. Werneck Vianna S, Werneck Vianna ML. Qual padrão de desenvolvimento? Cenários macroeconômicos no longo prazo. http://saudeama nha.fiocruz.br/sites/saudeamanha.fiocruz.br/ files/SA\%20-\%20TD\%2005.pdf (acessado em 17/ Jul/2015).

20. Carneiro R, Menicucci TMG. Gestão pública no Século XXI: as reformas pendentes. Brasília: Instituto de Pesquisa Econômica Aplicada; 2011. (Textos para Discussão, 1686).

21. Viana ALd'A, Miranda AS, Silva HP. Segmentos institucionais de gestão em saúde: descrição, tendências e cenários prospectivos. Rio de Janeiro: Fundação Oswaldo Cruz; 2015. (Textos para Discussão, 2).

22. Arretche M. Democracia, federalismo e centralização no Brasil. Rio de Janeiro: Editora FGV/Editora Fiocruz; 2012.

23. Santos BS. A reinvenção solidária e participativa do Estado. In: Santos BS, organizador. A gramática do tempo: para uma nova cultura política. v. 4. São Paulo: Cortez Editora; 2006. p. 341-76. (Coleção Para Um Novo Senso Comum).

Recebido em 28/Jul/2015

Aprovado em 29/Jul/2015 